\title{
Revisiting the Human-Society- Technology Nexus: Intercultural \\ Communication Studies as a Looking Glass for Scientific Self-Scrutiny in the Digital Human Sciences
}

Jonas Stier

\section{Introduction}

We-each one of us-live now, intermittently though quite often simultaneously, in two universes: online and offline. The second of the two is frequently dubbed "the real world," though the question whether such a label fits it better than it does the first turns more debatable by the day. ${ }^{\mathrm{I}}$ (Zygmunt Bauman)

More than 20 years ago, Manuel Castells ${ }^{2}$ was already referring to the information or network society as a key feature of late or liquid modernity, to use Zygmunt Bauman's term. ${ }^{3}$ Today, two

' Zygmunt Bauman, "Preface," in Digital Diversities, eds. Garry Robson and Malgorzata Zachara (Cambridge: Cambridge Scholars Publishing, 20I4), ix.

2 Manuel Castells, The Information Age: Economy, Society and Culture. Vol. I: The Rise of the Network Society (Oxford: Blackwell, I996); Manuel Castells, The Information Age: Economy, Society and Culture. Vol. II: The Power of Identity (Oxford: Blackwell, I997); Manuel Castells, The Information Age: Economy, Society and Culture. Vol. III: End of Millennium (Oxford: Blackwell, I998).

3 Zygmunt Bauman, Globalization: The Human Consequences (New York: Columbia University Press, I998); Zygmunt Bauman, Liquid Modernity (Cambridge: Polity Press, 2000).

How to cite this book chapter:

Stier, Jonas. "Revisiting the Human-Society-Technology Nexus: Intercultural Communication Studies as a Looking Glass for Scientific Self-Scrutiny in the Digital Human Sciences." In Digital Human Sciences: New ObjectsNew Approaches, edited by Sonya Petersson, 49-74. Stockholm: Stockholm University Press, 202I. DOI: https://doi.org/Io.I6993/bbk.c. License: CC-BY. 
decades later, digitalization (or digitization) is a frequent and popular word in public discourse. ${ }^{4}$ Policy-makers, "influencers," the "tech-industry," innovators, interest groups, researchers, and people in general, equally stress the importance and potential of digital technologies (DTs). ${ }^{5}$ It is often argued that DTs are preconditional to innovation and long-term development. Yet, they are both products of and vehicles of globalization. Such technologies are commonly put forward as the solution par excellence when it comes to ensuring and facilitating people's learning and self-realization, stimulating economic growth, or making production more efficient. Thus, DTs are preferred weapons to combat the "grand challenges" facing humanity-be those an aging population, finding cures for diseases, combating intolerance, or facilitating sustainable development. ${ }^{6}$

Parallel to this, there is a grand narrative of an ongoing, inevitable, and irreversible digital transformation impacting all areas of society. This said, DTs are disruptive to social order. ${ }^{7}$ For example, the American sociologist Richard Sennett argued as early as 20 years ago that the labor market has become increasingly flexible where limitlessness and insecurity are characteristics of work and employment. ${ }^{8}$ On the labor market, the current digitalization pertains to an overarching societal process where work previously performed by people becomes automated-that is, at an accelerating pace tasks are taken over by computers, robots, automated

4 Similarly, as Andersson Schwarz puts in elsewhere in this volume, "As research objects, digital media platforms are 'moving targets' in the sense that the sociocultural enactments taking place are ever-changing, making replication very hard."

5 For practical reasons, I discuss digital media, social media, and new media as parts of digital technologies.

${ }^{6}$ At the same time, Viktor Arvidsson and Anna Foka argue: "Despite the World Wide Web's (WWW) profound societal effects over the past two decades, social science and humanities research appear strangely transfixed by pre-Internet media, information, and communication theories" (no page). "Digital Gender: Perspective, Phenomena, Practice," First Monday 20, no. 4 (2015), https://doi.org/I0.5210/fm.v20i4.5930.

7 Guo-Ming Chen, “The Impact of New Media on Intercultural Communication in Global Context," China Media Research 8, no. 2 (2012): 5.

${ }^{8}$ Richard Sennett, The Corrosion of Character: The Personal Consequences of Work in the New Capitalism (New York: Norton, I998). 
systems, or algorithms. This means that jobs previously done by humans are taken over by machines, at the same time as new jobs are created. It also means that enormous volumes of data can be stored, processed, made accessible and used for different purposes and interests.

Furthermore, there is a steadily growing number of what Nikolaos Mavridis calls "disembodied or even physically embodied intelligent software agents" on social network sites-producing and making use of data. ${ }^{9}$ By the same token, digital products and services make up a constantly growing segment of global business and are today significant drivers of worldwide consumerism-once again using a term by Bauman. ${ }^{10}$ Against this background, the shift from a late modern information or network society to a digital society has steadily accentuated the last decade.

Three decades ago, it was already being claimed that globalization and late modernity had left people's identities increasingly problematic. ${ }^{\text {II }}$ It became more and more difficult for individuals to position themselves against traditional social categories such as class, culture, ethnicity, nationality, religion, or a given space or place. Bauman clearly envisioned that a characteristic of late modernity is constant movement-that is, even if we are physically still, we are in constant movement, traveling in physical space or cyberspace at an extreme pace. This movement leaves us nowhere for an extended period of time and makes us no more than visitors. ${ }^{12}$

Many claim that this social transformation has been accentuated in the new millennium. ${ }^{\mathrm{I} 3}$ Bauman argues that continuity and coherence have been replaced by discontinuity and lack of coherence, where time has fallen apart into events, happenings, adventures,

9 Nikolaos Mavridis, "Artificial Agents Entering Social Networks," in A Networked Self: Identity, Community, and Culture on Social Network Sites, ed. Zizi Papacharissi (New York, London: Routledge, 20I I), 29I.

to Zygmunt Bauman, Consuming Life (Cambridge: Polity Press, 2007).

II Anthony Giddens, Modernity and Self-Identity: Self and Society in the Late Modern Age (Cambridge: Polity Press, I99I); Castells, The Rise of the Network Society; Bauman, Liquid Modernity.

I2 Bauman, Globalization.

I3 Jonas Stier, (Van)modernitet och identitet (Lund: Studentlitteratur, 20I2). 
and episodes. ${ }^{\mathrm{I} 4}$ Similarly, the German sociologist Hartmut Rosa argues that society of today is characterized by an accelerating transformation pace. ${ }^{15}$ Rosa describes this transformation by distinguishing between three types of acceleration reciprocally affecting each other: "technical acceleration," "acceleration of social change," and "acceleration of "the pace of life." Such accelerations impact both people's sense of time and their relationships to DTs. In fact, these accelerations are made possible via DTs, and are at the same time accentuated by such technologies.

Undoubtedly, this temporal and spatial transformation and recent "digital turn" have implications for people's sense of identity microlevel human interaction as well as for culture and society as such. An increasing presence in cyberspace has, for instance, led us to introduce terms such "in real life" (IRL)—almost implying that direct verbal interaction is an everyday life anomaly. Thus, a growing number of media through which we can communicate with one another has replaced interaction where interlocutors are physically present in the same place. It can be, therefore, argued that life online is no longer separate from life offline. For instance, learning is more and more taking place via DTs-such "teachnology" is common practice for new generations in schools all around the world, even prior to the Covid-I9 pandemic. Moreover, DTs offer new arena for identity and Gemeinschaft. Guo-Ming Chen writes: "The time and space compression caused by the convergence of new media and globalization creates a universal cyberspace in which new cultural identity is merging in virtual communities." ${ }^{\prime 6}$

For the above reasons, it is often claimed that the overall digitalization of society, as well as the use of DTs for interaction purposes, constitutes one of the most profound transformations of human life. This said, there is a steadily growing volume of research and research methods addressing this change-focusing on a wide spectrum of aspects-innovation, design, digital readiness, digital

\footnotetext{
${ }^{14}$ Bauman, Consuming Life, 4 I.

${ }^{15}$ Hartmut Rosa, Social Acceleration: A New Theory of Modernity (New York: Columbia University Press, 2013).

i6 Chen, "The Impact of New Media," 5.
} 
literacy, security, integrity, or effects on human interaction and identity, to mention only a few. Particularly preoccupied with the dialectical relations between DTs, humans, culture, and society is what is called the human-society-technology-paradigm, and science, technology, and society studies, STS. ${ }^{17}$

This research notwithstanding, online life is still often understood as distinct and separated from the "ordinary aspects of the human experience." ${ }^{8} 8$ It is also striking how often such research and research methods are uninterested or insensitive to or altogether disregard the variation, diversity, and uniqueness of the cultural and societal backscene in the design of DTs, policies and overall discourses on digitalization, innovation, and DT development. Similarly, in public discourse DTs are often depicted as "objective" and void of cultural contents and underpinnings. As a friend of mine exclaimed, "In a nutshell, DTs are products of young, middle class Western males.” This is likely to have social implications:

The new culture hatched from new media creates a continuity gap between traditions and innovations within a culture. Before the emergence of new media [...] traditions and innovations in human society co-existed in a dynamically synchronized way, but the speed and impact of the new media resulted in the inability of traditional values to keep pace with the new cultural values produced by new media. This cultural gap has caused difficulty in understanding or communication between generations and among people in the same culture. ${ }^{19}$

Although these matters may be addressed by some researchers, typically within the humanities and social sciences, more elaborate analyses of implications, such as the ones above, are often left outside the overall discussion on digitalization and DTs. Similarly, there is still limited scientific literature and empirical research focusing on DTs, diversity, and intercultural communication—its dynamics, dilemmas, and inherent potential—making

\footnotetext{
${ }^{17}$ Worth reading is Melvin Kranzberg, "Science-Technology-Society: It's as Simple as XYZ!" Theory Into Practice 30, no. 4 (I99I): 234-24I.

I8 Arvidsson and Foka, "Digital Gender," no page.

19 Chen, "The Impact of New Media," 4.
} 
use of theories, concepts, and research from intercultural communication studies (ICCS). ${ }^{20}$

Against this background, the aim of this chapter is to discuss DTs in the light of the cultural and societal backscene-including what is referred to as the discursive blind spots-in the design of DTs, policies, and overall discourses on digitalization, innovation, and DT development. This is done in the light of theories, concepts, and research from ICCS, research methodology, interdisciplinarity, and a variety of examples. ${ }^{2 \mathrm{I}}$ Based on these discussions, the case is made that the digital human sciences (DHV) offer a valuable contribution to the scientific understanding of the manifestations and consequences of digitalization. In particular, this chapter argues for the usefulness of "intermethodological," interdisciplinary, intercultural, and integrative approaches in DHV.

\section{Discursive Blind Spots in DTs}

In the design of DTs, policies, and overall discourses on digitalization, innovation, and DT development, a number of discursive blind spots can be discerned. Drawing upon my own previous research, I propose a typology of blind spots. These are referred to as "technocentrism," "normativism," "homo- and heterocentrism," "human egocentrism and ethnocentrism," and "the reversed problem imperative." ${ }^{22}$

\section{Technocentrism and normativism}

Over the years, there have been multiple and slightly different understandings of the concept of technocentrism. ${ }^{23}$ Technocentrism

20 As exceptions to the claim made, see Garry Robson and Malgorzata Zachara, eds., "Introduction," in Digital Diversities (Cambridge: Cambridge Scholars Publishing, 20I4), I-9, or Margaret D'Silva and Ahmet Atay, Intercultural Communication, Identity, and Social Movements in the Digital Age (New York: Routledge, 2020).

2I I will use the term culture broadly, however, without elaborating on it.

22 Jonas Stier, "The Blind Spots and Biases of Intercultural Communication Studies: A Discussion on Episteme and Doxa in a Field," Journal of Intercultural Communication, issue 24 (October 20IO): I-I I.

23 See for instance Samuel Hays, Conservation and the Gospel of Efficiency (Cambridge, MA: Harvard University Press, I959); Seymour Papert, “A 
is seen here as the unreflected notion of DTs as something innately positive, with the capacity to be the tool par excellence to solve the grand challenges of humanity. Such a technocentric attitude, in addition to the recent elevation of digitalization, permeates much of public discourse, rendering it an almost hegemonic position, where the consideration to culture is largely absent or placed in the periphery of debate.

In the light of technology in general and DTs more specifically, technocentrism departs from several seldom explicated or scrutinized normative assumptions. One is that innovation and technological advancements (including the wider notion of digitalization) are often and unreflectively equalized with (or, some would argue, mistaken for) social development and economic growth, and are thereby viewed as a necessity for humanity. In the light of our discussion, DTs are viewed as the primary weapons to combat the "grand challenges" facing humanity.

In addition, there is also a sense of technological inevitabilityDTs are here to stay. While declining the prospect that DTs are conceived of as a nonoption, Unicorn HRO, a company offering digital technology solutions in the human resources sector, states:

In today's corporate world, businesses must always be willing to adapt to new developments and change. This is certainly true with regards to the rapid emergence of new technological innovations. While new technology can be utilized to help businesses run more efficiently and productively, employers may find that their employees are not initially willing to accept new technologies in the workplace. $^{24}$

Thus, there are divergent views on the usefulness and value of DTs among individuals, but at the collective level it is frequently posited that Swedish people hold relatively positive attitudes toward and have trust in DTs, and are relatively prone to adopt new DTscompared to many other countries. Despite such differences, on a global scale, DTs are becoming increasingly intertwined with not

Critique of Technocentrism in Thinking about the School of the Future," paper composed in I987; Stier, "The Blind Spots and Biases."

${ }_{24}$ Unicorn HRO website, "Handling Resistance to Technological Change in the Workforce," https://unicornhro.com/blog/handling-resistance-to-tech nological-change-in-the-workforce. 
only with people's lifestyle but with their identity. Using the ideas of Erving Goffman, ${ }^{25}$ more and more of people's "face-work" takes place via Facebook, Instagram, Twitter, Tinder, or LinkedIn, rendering DTs an increasing importance for their self-definition. ${ }^{26}$ Or, citing Grant Bollmer:

Our identities and bodies are quite literally shaped by the material and technical means we have for recording information and communicating. This does not mean that we are nothing other than our data, or that we do not exist outside the technologies we use. But it does mean that our sense of self and our physical sense of embodiment are both shaped by the media we use. Our identities are reimagined according to how media permit our bodies to interact. ${ }^{27}$

In the discourse, the absence of change and the presence of stability (i.e., the lack of innovation and technological advancements) are typically described in terms of unproductive stagnation or even disintegration, which in turn is conceived of as a threat to social development and long-term human prosperity. Both the precedence of development and change presupposes a strong sense of individual agency and a cultural preference for "doing" rather than "being" or "being-in-becoming"—something that in ICCS is referred to as activity orientation. ${ }^{28}$ I found an example of this preoccupation with change and doing in a blog by Torben Rick, a senior executive with experience from management consulting and from the telecom sector: "[In digital transformation] [b]uilding a culture of constant change-a state of constant revolution is key." 29

25 Erving Goffman, The Presentation of Self in Everyday Life (New York: Doubleday, I959).

26 Jonas Stier, (Van)modernitet och identitet (Lund: Studentlitteratur: 20I2).

${ }_{27}$ Grant Bollmer, Theorizing Digital Cultures (Thousand Oaks, CA: SAGE, 20I8), I I6.

${ }_{28}$ Florence Kluckhohn and Fred Strodtbeck, Variations in Value Orientations (New York: Row and Peterson, I96I); William Gudykunst and Young Yun Kim, Communicating with Strangers: An Approach to Intercultural Communication, 4th ed. (Boston, MA: McGraw-Hill, 2003).

29 Torben Rick, "Culture Change Is Key in Digital Transformation," blog, September9, 20I7, https://www.torbenrick.eu/blog/culture/culture-changeis-key-in-digital-transformation. 
This means that, in doing-oriented cultures (Sweden or the US), activities focus on results that are "external to the individual, which can be measured by someone else. Activities must be tangible." ${ }^{\circ}$ In such societies, social status and individual self-worth is to a higher extent derived from accomplishments and achievements, whereas in more being-oriented cultures (e.g., parts of the Middle East), more emphasis is on "a spontaneous expression of what is conceived to be 'given' in the human personality." ${ }^{\text {I }}$ One's background and who one is have a greater significance for status and self-worth. In being-in-becoming societies (for instance, where Buddhism is predominant) concern is less on what people achieve and more on who they are and how they can become "an integrated whole in the development of the self." ${ }^{2}$

With this threefold distinction of activity orientation in mind, innovation and digitalization as they are often portrayed in public discourse draw from individual agency and proactivity, and are presumably more consistent with doing-cultures and being-in-becoming cultures than pronounced being-cultures. Although this largely remains an empirical question, one might think that DTs could serve to fulfill the ends of the other activity orientations as well.

Moreover, in discourse digitalization is depicted as a double-edged sword. On the one hand, DTs are often viewed as the paramount vehicles to change-be it for society, an organization, or the individual. DTs can and should, for instance, help us to protect, manage, and control nature/the environment. DTs are to facilitate sustainable development and assist us in combating poverty, criminality, or extremism, or reducing carbon dioxide emissions or making welfare systems more resilient. Or, with reference to common concerns of ICCS, DTs may provide means to counteract prejudice, ethnocentrism, cultural clashes, racism, and hatred with roots in dysfunctional communication across cultural boundaries. ${ }^{33}$ Yet another example is how the educational sector

\footnotetext{
$3^{\circ}$ Gudykunst and Kim, Communicating with Strangers, 84 .

${ }^{31}$ Kluckhohn and Strodtbeck, Variations in Value Orientations, I 6.

${ }^{32}$ Gudykunst and Kim, Communicating with Strangers, 84.

33 Jonas Stier, "The Blind Spots and Biases."
} 
in Sweden is working hard to implement digital "teachnology," which is said to optimize learning and knowledge production:

Edmodo is an educational tool that connects teachers and students, and is assimilated into a social network. In this one, teachers can create online collaborative groups, administer and provide educational materials, measure student performance, and communicate with parents, among other functions. Edmodo has more than 34 million users who connect to create a learning process that is more enriching, personalized, and aligned with the opportunities brought by technology and the digital environment. ${ }^{34}$

Advertisements typically portray DTs as good, time-efficient, and status-providing-for example, successful people are busy, want to make a difference, and therefore early adopters of new DTs offered to them at a "good" price. Such representations convey the idea that new DTs are good per se.

The underlying reasons for "selling" DTs are, of course, both commercial and political. Today, DTs are seen as instrumental drivers of capitalism and for what Bauman calls consumerism. ${ }^{35}$ Therefore, potential downsides or challenges following digitalization (e.g., risks with self-driving cars, personal data leakage, facial recognition, or autonomous weapon systems) are discursively constructed as either acceptable in the light of their foreseeable (positive) effects, manageable or transitory. Solutions or the failure of finding such solutions are typically attributed to the attitude or capacities of the individuals involved, be they citizens, consumers, politicians, students, or researchers in the human, legal or social sciences. Thus, the minority who do not adopt to the new technologies are criticized or dismissed as backward skeptics or "refusers," whereas the vast majority eventually will see the light.

On the one hand, digitalization per se is described as a challenge that must be managed-including for commercial and political reasons. In the light of their mission to facilitate Sweden's economic competitiveness, the Swedish Agency for Economic and

\footnotetext{
34 eLearning Industry website, "I I Digital Education Tools for Teachers and Students,” https://elearningindustry.com/digital-education-tools-teachers -students.

35 Bauman, Consuming Life.
} 
Regional Growth (Tillväxtverket) stresses the need for all sectors in society to master and take advantage of digitalization to ensure Sweden's competitiveness on the global market.

\section{Homo- versus heterocentrism}

In ICCS, the preoccupation with difference and variation is almost axiomatic. A bedrock assumption is that people, cultures, ethnicities, religion, and languages are dissimilar and that such dissimilarities are the roots of misunderstandings, clashes, or conflicts. To address such cultural variation, the works of Edward Hall, ${ }^{36}$ Geert Hofstede, ${ }^{37}$ and the World Values Survey are commonly referred to. Such variation has implications for social interaction. When cultural differences are at play, individuals engage themselves in intercultural communication. Everett Rogers and Thomas Steinfatt define intercultural communication as:

the exchange of information between individuals who are unalike culturally. This broad definition implies that two or more individuals may be unalike in their national culture, ethnicity, age, gender, or in other ways that affect their interaction. Their dissimilarity means that effective communication between them is particularly difficult. The cultural unalikeness of the individuals who interact is the unique aspect of intercultural communication..$^{3}$

Intercultural communication also pertains to interplay (voluntary or involuntary, intentional or unintentional), where the interlocutors construct one another as strangers or different in some respects. ${ }^{39}$ In the humanities and social sciences, processes of "othering" and "difference" are focal concerns and there is an ample literature on what Bauman refers to as heterophily, ${ }^{40}$ the degree to

${ }^{36}$ Edward Hall, The Silent Language (Greenwich: Fawcett, I959); Edward Hall, The Hidden Dimension (New York: Doubleday, I966); Edward Hall, Beyond Culture (Garden City: Anchor Press, I976).

37 Geert Hofstede, Culture's Consequences (Beverly Hills, CA: Sage, I979); Geert Hofstede, Culture and Organizations (London: McGraw-Hill, I99I).

${ }^{8}$ Original emphasis. Everett Rogers and Thomas Steinfatt, Intercultural Communication (Long Grove, IL: Waveland Press, I999), 79.

39 Gudykunst and Kim, Communicating with Strangers.

$4 \circ$ Zygmunt Bauman, Modernity and the Holocaust (Cambridge: Polity Press, I989). 
which people are (perceiving one another as) unlike, ${ }^{4 \mathrm{I}}$ and notions of difference, deviance, and outsiders. ${ }^{42}$ These socially constructed notion of difference, deviance or outsider-ness are embedded in language-for example, in dichotomies such as: Swedes/nonSwedes, similar/dissimilar, different/not different, like/unlikeand fuel the idea of humanity as one of mainly multiplicity and diversity, not of community and universal qualities.

However, in the field of digitalization, distinctions and differences yield to unreflected universalism-at least at the collective level, where people are viewed as an almost monocultural collective, albeit different in their capacities, literacy, or susceptibility to new DTs. Thus, by contrast to the assumptions of ICCS, technocentrism and normativism are commonly anchored in ideas of a homogenous world, where DT design is featured by both cultural universalism ("one size fits all") and individualism (DTs help me to find my personal lifestyle, define me as a person, or enable self-actualization). Considering globalization and generational differences in the uptake of DTs, such a universalism may create boundaries between people, both within and between countries and cultures. Chen writes:

New media also extrinsically breeds communication gaps between different cultural and ethnic groups. The fragmented nature of new media has switched traditional cultural grammar, cultural themes, or cultural maps to a new pattern, resulting in the loss of traditional cultural logic.43

Even if there are analyses and theorizations, such as the one above, on innovation, technological development, and DTs, which account for human diversity, much of the discourse on the human-society-DTs nexus fail to consider cultural diversity or intercultural communication-and the potential consequences of digitalization on intercultural communication. When diversity and cultural variations are recognized, it is often more at a rhetorical level than genuinely and elaborately accommodating for such variation.

\footnotetext{
${ }^{4}$ See, e.g., Rogers and Steinfatt, Intercultural Communication.

${ }^{42}$ See Howard Becker, Outsiders: Studies in the Sociology of Deviance (New York: The Free Press, I963).

43 Chen, "The Impact of New Media," 4.
} 
Another aspect of heterocentrism is the culturally constructed distinctions between humans and machines, or between society and DTs. These distinctions are ontological, epistemological, and axiological in nature. Concretely, this means that reality is seen as consisting of the qualitatively distinct entities we refer to as humans and machines. Expressed in the language of homocentrism, humans and machines are ascribed different ethics (in most cases, the value of a person supersedes that of a machine). When these epistemologies are established, and in Peter Berger and Thomas Luckmann's terminology are "objectified," 44 they underscore their own ontology. But previous objectivation also changes. For example, the dissolution of boundaries between man and machine has led to new words such as "cyborgs" or "bots" and may eventually lead us to change our use of pronouns, or introduce a new noun for an entity "in-between" a human and a machine. Over time, this can presumably make us less prone to think of and maintain the distinction between people and machines, though this calls for empirical research in the future.

\section{Human egocentrism and ethnocentrism}

Human beings are egocentric: 45 we are the subjects of our own experience of the world and the world gravitates around us as experiencing subjects. This has at least two implications. The first is that it appears as if we largely fall into seeing the world from our own perspective. ${ }^{46}$ The second is that we cannot observe ourselves as observers and co-constructors of reality. So, as we use DTs, it provides us with a personal, yet culturally contingent and ethnocentric, window to the world. This means that our experience is formed experience against the backscene of society and culture. Society and culture serve as lenses of the culture and society we have internalized-for example, norms, values, meanings, world views, ideologies, and language. Once internalized, we take it for

44 Peter Berger and Thomas Luckmann, The Social Construction of Reality: A Treatise in the Sociology of Knowledge (London: Penguin Books, I966).

45 In the sense here, egocentrism should not be mistaken for selfishness.

${ }_{46}$ To compensate for this, the importance of empathy, perspective-alteration, and mindfulness is often stressed. 
granted, at the same time as we tend to favor our culture more than others. This is usually referred to as ethnocentrism. ${ }^{47}$ For these reasons, our experience of the world provides merely an ethnocentric (and personalized) version of the world. $4^{8}$

As an example, we can look at the notion of privacy. Cultural codes stipulate whether a space is private or public or, in some instances, semiprivate. ${ }^{49}$ As such, we see it both as taken for granted and "right" that our home is a private place where nonstrangers need permission to enter. There are variations in how accessible our home is to nonfamily members. Neighbors, acquaintances, or friends may be free to enter some areas (e.g., the living room), whereas this is not norm-consistent in others (e.g., the bedroom).

In many ways, DTs dissolve the notion of privacy, or at least redefine it. Today, you may be physically isolated or secluded in physical space, yet by being online we are open to the world and an indefinite number of places. Or perhaps we are members of a virtual place (e.g., a digital community). Thus, with DTs, new ways of maintaining and constructing the notion of privacy develop. The greater openness and access to the world, the more permeable one's personal boundaries to other people becomewhich, paradoxically enough, the less control and self-autonomy one may feel.

However, privacy extends beyond space and place, physical or virtual, and ties into personal integrity. In our part of the worldthat is, a highly individualistic culture ${ }^{\circ}$ — such integrity is associated (and even regulated) in relation to the person. In collectivistic cultures, integrity has a wider meaning, including not merely immediate family but extended family or the local community. The point is that when discussing integrity with regard to DTs an individualistic notion of integrity is implied or presupposed. Little

47 Marilynn Brewer and Donald Campbell, Ethnocentrism and Intergroup Attitudes (New York: Wiley, I976).

${ }^{4}$ See, e.g., William Sumner, Folkways: A Study of the Sociological Importance of Usages, Manners, Customs, Mores, and Morals (Boston, MA: Ginn \& Co, I906).

49 Hall, The Hidden Dimension; Gudykunst and Kim, Communicating with Strangers.

5० For an elaboration of the meaning of the term, see Gudykunst and Kim, Communicating with Strangers. 
consideration is taken of the more collectivistic understanding of privacy.

The notion of time serves as another example. DTs both presuppose a certain notion of time and impact on people's sense of time. Yet, in this domain of society there are also cross-cultural variations. Using the concepts of monochronic and polychronic time cultures, cultures and societies differ in the relation to time. ${ }^{\text {I }}$ In the Nordic countries, a monochronic time conception is common. It means that time is understood as linear-it is important, bought, lost, or killed. Time is managed and related to efficiency (and thereby the prospect of saving-or wasting-money!) as we plan, follow through, and follow up. Social expectations prescribe promptness and punctuality. By contrast, polychronic time cultures often adhere to a more cyclical view of time and is less preoccupied with time management and punctuality. Bringing DTs into the equation, common practice is to market new digital tools as "time-saving." In polychronic time cultures, the selling argument is more likely to be "status."

Drawing upon Bauman's and Rosa's writings, ${ }^{52}$ digitalization fuels the transformation of time-a subsequent question is whether or not polychronic time conception will eventually have to yield to monochronic ones. With this in mind, it seems reasonable that a monochronic notion of time is more consistent with DTs than polychronic ones. Yet, regardless of collective notions of time, individuals may be more or less susceptible to the predominant time conceptions in the society in which they live, and as a consequence to DTs. Also, in this area, more humanistic and social scientific research is called for.

Just like time conceptions, DTs are extensions of culture; they mirror the culture in which they are designed. ${ }^{53}$ Thus, embedded in DTs are symbols, words, images, colors, meanings, and communicative codes. Similarly, culture is embedded in discourses (e.g., policies, curricula, and mission statements) on DTs. For

${ }^{5}$ Hall, The Silent Language; Gudykunst and Kim, Communicating with Strangers; Jonas Stier, Kulturmöten - En introduktion till interkulturella studier (Lund: Studentlitteratur, 2019).

$5^{2}$ Bauman, Consuming Life; Rosa, Social Acceleration.

${ }_{53}$ Hall, Beyond Culture. 
these reasons, any producer or consumer of such technologies must possess a certain level of cultural competence, since the digital domain is largely permeated by a "Western model of thinking" and typically only marginal adjustments are made for "cultural reasons." But DTs also contribute to the formation of cultural forms. As people adopt DTs, new digital cultures are formed, with unique norms, terminologies, world views, and communities, which in turn affect people's identities and social relations. ${ }^{54}$

\section{The reversed problem imperative}

In ICCS, the problem imperative denotes a discursive tendency to "culturalize"- that is, to assume that culture, more than anything else, determines people's actions, or causes interpersonal conflicts, clashes, and communication problems. ${ }^{55}$ Overall, cultural differences and multicultural contexts are presumed to lead to more problems than cultural homogeneity. Similarly, culture serves as a "garbage can explanation" for communication breakdowns, conflict, management styles, views on gender equality, criminality, poor health, marginality, etc., whereas intersectional analyses still are more uncommon. ${ }^{56}$

When it comes to cross-cultural variations leading to misunderstandings and problems, language and symbols are perhaps most obvious. Languages provide insights into cultures and thereby influence the way we see the world. Thus, different languages provide different world views. In the case of DTs, it is fair to claim that English is not merely the lingua franca, but the entire discussion around digitalization or digital design takes an Anglo-Saxon world view as the point of take-off (reading from left to right, that green means "ok" and red "no"-to mention just two examples).

For this reason, when discussing DTs, the commonly stressed distinction between high- and low-context cultures in ICCS needs to be accounted for. ${ }^{57}$ In high-context cultures, a greater portion of the communicative message is located in the communicative situation (and less in the verbal) message, whereas the

\footnotetext{
54 See Bollmer, Theorizing Digital Cultures.

55 Stier, "The Blind Spots and Biases."

${ }_{56}$ Stier, Kulturmöten.

57 Hall, Beyond Culture.
} 
verbal message carries more weight in low-context communication. Similarly, codes surrounding communication vary between different parts of the world: how formal or informal one is when communicating with a stranger, power distance and status, prosody and nonverbal language, and assertiveness..$^{58}$ Many of these aspects may be less salient or a lost when communicating via DTs. Yet, if we refrain from recognizing their importance, they may cause misunderstandings and problems.

It can be assumed that digitally mediated communication exhibits more similarities to low-context communication than high-context communication. Thus, both the design of DTs rests on and better suits low-context communication, thereby suggesting the existence of fewer "problems" in digitally mediated communication in low contexts cultures. However, in low-context communication the absence of contextual cues may also be a challenge. Thus, to denote contextual information new symbolic systems evolve. Emojis, smileys, and abbreviations such as IRL or LOL are used on a global scale nowadays. In addition, there are idiosyncratic digitally related symbols in different countries. For the Swedes, “att sms:a" denotes "to text" with, for instance, your smartphone and for the German a "handy" is a cellular or mobile phone.

Despite what has been said, in discussions on DTs, culture and cultural variations are largely tucked away. Culture is simply not present or accounted for. Such a reversed problem imperative means that DTs are placed outside and above the realms of the cultural and social. They are given a status of being value-free, objective, and void of ideological and political underpinnings and consequences. Although questions of personal integrity and security have rendered some attention, foreseeable implications for democracy, citizenship, and interpersonal interaction still need more debate and analyses. This has drawn increasing attention, in the field of education, to what commonly is referred to as digital literacy. On the online learning platform Study.com, one can read:

${ }^{5}$ Hall, The Silent Language; Judee Burgoon, David Buller, and William Woodall, Non-Verbal Communication: The Unspoken Dialogue (New York: McGraw-Hill, I996). 
The internet, search engines, email programs, blogs, and online videos have all contributed to our expanding knowledge and capabilities. Proper selection, use and understanding of these tools is a capability known as digital literacy [...]. Digital literacy is the ability to navigate various digital platforms and understand, assess and communicate through them. ${ }^{59}$

Nevertheless, in an increasing global and multicultural world digital literacy needs to be accompanied by intercultural competence-not merely linguistic skills but also those pertaining to cultural codes, norms, values, proxemics, and cultural self-awareness, ${ }^{60}$ to mention only a few. In providing the scientific basis for this, ICCS has a key role to play.

\section{DHV as a Way of Revisiting the Human-Society- Technology Nexus}

In one way or another, the overarching endeavor in science and research is to deconstruct complexity and then reassemble it to make it comprehendible, predictable, or meaningful. For much of the humanities and legal and social sciences, this endeavor entails the tripodal study of the relationship between individual and society, human variation and similarities, and social change. Grappling with this tripodal concern in relation to the complexity and multiplicity of digitalization and DTs is a key endeavor for DHV.

A vital DHV does not merely shed light upon or problematize the technological, societal, or human side of things, but on the dialectical nexus of the three. By being interdisciplinary and intermethodological, DHV offer valuable theoretical and methodological tools for understanding and problematizing how digitalization and DTs transform culture, society, the world, and the notion of humans. ${ }^{6 \mathrm{I}}$

59 Study.com website, "What Is Digital Literacy? - Definition \& Example," https://study.com/academy/lesson/what-is-digital-literacy-definition -example.html.

60 Jonas Stier, "Internationalisation, Intercultural Communication and Intercultural Competence," Journal of Intercultural Communication, issue I I (April 2006): I-II.

6r Interdisciplinarity as a matter of "researcher disciplinary representation" needs to yield to authentic researcher collaboration, where colleagues 
Yet, all too often, analyses and theorizations of the human-society-technology nexus and on how DTs and overall digitalization, man, and society affect one another do not account for cultural diversity or digitally mediated intercultural communication. Rather, in DT design and in the discourse on digitalization there are several blind spots in ontology and epistemology and in research approaches targeting the human-society-DTs nexus. To study and problematize these blind spots and their implications is a matter for DHV.

Another case for DHV is found in recent innovations where technology is increasingly inserted into the human body to compensate for physical or psychological shortcomings or to cure medical conditions or simply to improve personal characteristics that individuals are dissatisfied with, which redefines the very old boundaries between human and nonhuman agents and qualities. ${ }^{62}$ This, as well as DTs and digitalization as such, brings about a wide array of potential consequences for individual integrity, the manifestations and global distribution of high- and low-context communication or mono- and polychronic time conceptions. Will DTs eventually render low-context communication and monochronic time conceptions hegemonic positions in the world? To understand and problematize these questions, DHV need to a higher extent to integrate theories, empirical findings, and not the least, deconstructive perspectives from ICCS.

Furthermore, DTs are likely to continue transforming the form and execution of research. Whereas there is a proxy between quantitative research and big data, it is less so when it comes to qualitative methodology. However, DTs have made their way into qualitative research methodology and will most likely change the ways of conducting conversation analysis, discourse analysis, ethnography observations, interviews, etc., in the human, legal,

from different disciplines or fields are jointly and truly involved in the research design, data collection, and data analysis. If such research collaboration happens, the chances of unraveling, problematizing, and accounting for the complexity in the society-human-DTs nexus are increased.

${ }^{62}$ Rosi Braidotti, The Posthuman (Cambridge: Polity Press, 2013); Francesca Ferrando, "Posthumanism, Transhumanism, Antihumanism, Metahumanism, and New Materialisms: Differences and Relations," Existenz 8 , no. 2 (2013): 26-32. 
and social sciences. Classic close reading of data (e.g., texts or artifacts) or analyses of multimodal interaction and representation are already complemented with new forms of ethnography and new DTs. For instance, sophisticated machine learning and artificial intelligence can be useful for qualitative data compilation and analysis, with regard to a variety of empirical contexts, including social media or the internet as such, will benefit DHV. Similarly, DTs play an increasingly important role in the cultural heritage sector, museum, libraries, and galleries. ${ }^{63}$ Yet, digital research tools-as well as the methodology itself-need to be more sensitive to cross-cultural variations (e.g., communicative codes, stipulating for example prosody, pauses, directness, and frankness).

DHV have much to gain from being integrative, that is, to a larger extent join theory and practice, research and DTs use, or research and technologically oriented education. DHV can bridge scientific approaches and research findings with the professional (or commercial) realms, as research-informed design, good practice examples or methodologies. Reversibly, the professional domain may supply DHV with urgent research topics and serve as a benchmark to assess the adequacy and relevance of research. Such an integrative approach is enriching for all actors involved and may stimulate co-creative, interprofessional, and actionemancipatory approaches. This is consistent with the ambitions of open science. ${ }^{64}$

\section{A Way Forward}

It seems almost like a truism to claim that digitalization and DTs cut at across and have collective level homogenizing effects in all domains of everyday life and culture, or that digitalization

\footnotetext{
${ }_{3}$ See Fiona Cameron and Sarah Kenderine, Theorizing Cultural Heritage (Cambridge, MA: MIT Press, 2010)

${ }^{64}$ Increasingly, it is stressed that higher education and research needs to play a key role in development, innovation, and in the accommodation of the great challenges facing mankind. It is in this light the former EU-Commissioner Carlos Moedas' "three o-strategy" is to be seen: "Open Innovation, Open Science and Open to the World." European Commission website, "Open Innovation, Open Science, Open to the World - A Vision for Europe,” https://ec.europa.eu/digital-single-market /en/news/open-innovation-open-science-open-world-vision-europe.
} 
fuels the transformation of time and space. Consistent with the human-society-technology paradigm and science, technology, and society studies, the thesis put forward here has been that culture, technology, and individuals exist in a dialectical or, some would argue, symbiotic relationship. DTs are products of societies and culture where people design new technologies and use such technologies for self-presentation and self-representation. ${ }^{65}$ Concurrently, these technologies have intended or unintended consequences for societies, culture and people-their everyday life, modes of communication, world views, time conceptions, and, at a deeper level, how they view themselves as individuals, groups, or humans. ${ }^{66}$ But unintended consequences may not always be negative. Looking at social media, for instance, with reference to Agnieszka Stasiewicz-Bienkowska, Garry Robson and Malgorzata Zachara write:

there is the potential of Facebook, Skype and the rest to aid sojourners in their attempt to manage feelings of vulnerability and dislocation early in their stay; as a set of tools and practices with which to convert the vulnerabilities and insecurities of depersonalized space into places which can be experienced as safe, solid and restful. ${ }^{67}$

It has been argued that cultural diversity and human variation often are downplayed or overlooked both in public discourse and in scientific approaches to the human-society-DTs nexus. Similarly, the cultural underpinnings of digitalization and DTs and crosscultural variations with potential impact on people, society, and DTs need to be accounted for, with regard to high and low-context cultures, "being" and "doing" cultures, notions of time, privacy and integrity, to mention a few. Thus, discursive blind spots-that is, normativism and technocentrism, homo- and heterocentrism, human egocentrism and ethnocentrism, and the reversed problem imperative-may entrap us in an epistemological tunnel vision.

Today it seems fair to say that there is a growing realization that digitalization and DTs are a much too complex and voluminous

${ }_{5}$ See Nancy Thumim, Self-Representation and Digital Culture (London: Palgrave Macmillan, 20I2).

${ }^{66}$ Kranzberg, "Science-Technology-Society."

${ }^{67}$ Robson and Zachara, "Introduction," 3. 
matter for any sector in society or academic discipline to manage. Instead, in an increasingly digitalized, diverse, and dynamic world, traditional monodisciplinary approaches risk falling short, calling for multifactorial and interdisciplinary approaches when unraveling the human-society-DTs nexus-in computer science ${ }^{68}$ and DTs design too. This demands that the human, legal, and social sciences are proactive and willing to renew themselves. Being interdisciplinary and "intermethodological," DHV are well equipped to explore and understand the human-society-DTs nexus, digitalization, and their implications for humans, culture, and society. To be even better equipped in this endeavor, it has been argued that DHV have much to gain from using of ICCS theories-as well as from intersectional, posthumanistic, and postcolonial perspectives. ${ }^{69}$

Although DHV need to be critical toward DTs, they have much to gain by being open to them as research tools for data collection and data analysis and may, over time, be more efficient in accounting for and enabling cross-cultural and comparative analyses, for example when it comes to communicative codes, symbols, the use of rhetorical resources, metaphors, or prosody.

Let me close with three statements from the online description of Rongie Bolanos's book Digital Communications: Fundamentals and Applications (2016), ${ }^{\circ}$ where the first is almost apocalyptic: "Modern day life is consumed by technology. Without it, life would not be nearly the same. The digital world is growing bigger and more powerful." Statements like this one tell us why DHV are crucial. Perhaps the most important role of DHV is its deconstructive and critical views, for instance targeting the presupposition of cultural, ideological, or social homogeneity or epistemological dichotomies anchored in cultural ontologies-for example, that there is a qualitative and ethically motivated distinction between humans and machines or between society and DTs. Also, DHV

68 See, e.g., Brian Christian and Tom Griffith, Algorithms to Live By (London: William Collins, 20I7).

69 Braidotti, The Posthuman; Ferrando, "Posthumanism, Transhumanism, Antihumanism, Metahumanism.”

70 Rongie Bolanos, Digital Communications: Fundamentals and Applications (Burlington: Delve Publishing, 2016). 
offer both retrospective and future-oriented analyses of the outcomes and consequences of digitalization and the use of DTs-on humans and society. Because, no matter what, two things ought to be certain-the world is always changing, and so are we, and we are never fully able to see what the future holds for us. Echoing the line of Bob Dylan, "You better start swimmin' or you'll sink like a stone, for the times they are a-changin'."

\section{References}

Arvidsson, Viktor, and Anna Foka. "Digital Gender: Perspective, Phenomena, Practice.” First Monday 20, no. 4 (20I 5): unpaginated. https://doi.org/I0.52 Io/fm.v20i4.5930

Bauman, Zygmunt. Globalization: The Human Consequences. New York: Columbia University Press, I998.

Bauman, Zygmunt. Liquid Modernity. Cambridge: Polity Press, 2000.

Bauman, Zygmunt. Liquid Fear. Cambridge: Polity Press, 2006.

Bauman, Zygmunt. Consuming Life. Cambridge: Polity Press, 2007.

Becker, Howard. Outsiders: Studies in the Sociology of Deviance. New York: The Free Press, I963.

Berger, Peter, and Thomas Luckmann. The Social Construction of Reality: A Treatise in the Sociology of Knowledge. London: Penguin Books, I966.

Bolanos, Rongie. Digital Communications: Fundamentals and Applications. Burlington: Delve Publishing, 2016.

Bollmer, Grant. Theorizing Digital Cultures. Thousand Oaks, CA: SAGE, 2018.

Braidotti, Rosi. The Posthuman. Cambridge: Polity Press, 2013.

Brewer, Marilynn, and Donald Campbell. Ethnocentrism and Intergroup Attitudes. New York: Wiley, 1976.

Burgoon, Judee, David Buller, and William Woodall. Non-Verbal Communication: The Unspoken Dialogue. New York: McGrawHill, 1996.

Cameron, Fiona, and Sarah Kenderine. Theorizing Cultural Heritage. Cambridge, MA: MIT Press, 20 Iо. 
Castells, Manuel. The Information Age: Economy, Society and Culture. Vol. I: The Rise of the Network Society. Oxford: Blackwell, I996.

Castells, Manuel. The Information Age: Economy, Society and Culture. Vol. II: The Power of Identity. Oxford: Blackwell, I997.

Castells, Manuel. The Information Age: Economy, Society and Culture. Vol. III: End of Millennium. Oxford: Blackwell, I998.

Chen, Guo-Ming. "The Impact of New Media on Intercultural Communication in Global Context." China Media Research 8, no. 2 (2OI 2): I-IO.

Christian, Brian, and Tom Griffith. Algorithms to Live By. London: William Collins, 2017.

D'Silva, Margaret, and Ahmet Atay. Intercultural Communication, Identity, and Social Movements in the Digital Age. New York: Routledge, 2020.

Dylan, Bob. "The Times They Are a-Changin'." From the album The Times They Are a-Changin', 1964.

eLearning Industry website. “I I Digital Education Tools for Teachers and Students." https://elearningindustry.com/digital-education-tools -teachers-students.

European Commission website. "Open Innovation, Open Science, Open to the World - A Vision for Europe." https://ec.europa.eu /digital-single-market/en/news/open-innovation-open-science -open-world-vision-europe.

Ferrando, Francesca. "Posthumanism, Transhumanism, Antihumanism, Metahumanism, and New Materialisms: Differences and Relations." Existenz 8, no. 2 (2013): 26-32.

Giddens, Anthony. Modernity and Self-Identity: Self and Society in the Late Modern Age. Cambridge: Polity Press, I99I.

Goffman, Erving. The Presentation of Self in Everyday Life. New York: Doubleday, 1959.

Gudykunst, William, and Young Yun Kim. Communicating with Strangers: An Approach to Intercultural Communication. 4th ed. Boston, MA: McGraw-Hill, 2003.

Hall, Edward. The Silent Language. Greenwich: Fawcett, I959. 
Hall, Edward. The Hidden Dimension. New York: Doubleday, 1966. Hall, Edward. Beyond Culture. Garden City: Anchor Press, I976.

Hall, Edward. The Silent Language. New York: Anchor Books, I98 I. Hays, Samuel. Conservation and the Gospel of Efficiency. Cambridge, MA: Harvard University Press, I959.

Hofstede, Geert. Culture's Consequences. Beverly Hills, CA: Sage, I 979.

Hofstede, Geert. Culture and Organizations. London: McGraw-Hill, I99I.

Kluckhohn, Florence, and Fred Strodtbeck. Variations in Value Orientations. New York: Row and Peterson, I96r.

Kranzberg, Melvin. "Science-Technology-Society: It's as Simple as XYZ!” Theory Into Practice 30, no. 4 (I99I): 234-24I.

Mavridis, Nikolaos. "Artificial Agents Entering Social Networks.” In A Networked Self: Identity, Community, and Culture on Social Network Sites, edited by Zizi Papacharissi, 29I-303. New York, London: Routledge, 20 I I.

Papert, Seymour. "A Critique of Technocentrism in Thinking about the School of the Future." Paper composed in I987. http://www .papert.org/articles/ACritiqueofTechnocentrism.html.

Rogers, Everett, and Thomas Steinfatt. Intercultural Communication. Long Grove, IL: Waveland Press, I999.

Robson, Garry, and Malgorzata Zachara, eds. "Introduction.” In Digital Diversities, I-9. Cambridge: Cambridge Scholars Publishing, 2OI4.

Rosa, Hartmut. Social Acceleration: A New Theory of Modernity. New York: Columbia University Press, 2013.

Sennett, Richard. The Corrosion of Character: The Personal Consequences of Work in the New Capitalism. New York: Norton, I998.

Stier, Jonas. "Internationalisation, Intercultural Communication and Intercultural Competence." Journal of Intercultural Communication, issue I I (April 2006): I-I I. 
Stier, Jonas. "The Blind Spots and Biases of Intercultural Communication Studies: A Discussion on Episteme and Doxa in a Field," Journal of Intercultural Communication, 24 (October 20IO): I-I I.

Stier, Jonas. (Van)modernitet och identitet. Lund: Studentlitteratur, $20 \mathrm{I} 2$.

Stier, Jonas. Kulturmöten - En introduktion till interkulturella studier. Lund: Studentlitteratur, 2019.

Study.com website. "What Is Digital Literacy? - Definition \& Example.” https://study.com/academy/lesson/what-is-digital-literacy -definition-example.html.

Thumim, Nancy. Self-Representation and Digital Culture. London: Palgrave Macmillan, 20I 2.

Torben Rick blog. "Culture Change Is Key in Digital Transformation.” September 9, 20I 7. https://www.torbenrick.eu/blog/culture/culture -change-is-key-in-digital-transformation.

Unicorn HRO website. "Handling Resistance to Technological Change in the Workforce." https://unicornhro.com/blog/handling -resistance-to-technological-change-in-the-workforce.

World Values Survey website. http://www.worldvaluessurvey.org/wvs .jsp. 